\title{
Enterococcal surface protein contributes to persistence in the host but is not a target of opsonic and protective antibodies in Enterococcus faecium infection
}

\section{Correspondence \\ J. Huebner \\ johueb@gmail.com}

Received 15 March 2010

Accepted 2 June 2010

\author{
I. G. Sava, ${ }^{1}$ E. Heikens, ${ }^{2}$ A. Kropec,${ }^{1}$ C. Theilacker, ${ }^{1}$ R. Willems ${ }^{2}$ \\ and J. Huebner ${ }^{1}$
}

${ }^{1}$ Division of Infectious Diseases, Department of Medicine, University Medical Center, Hugstetter Str. 55, 79106 Freiburg, Germany
${ }^{2}$ Department of Medical Microbiology, University Medical Center Utrecht, Heidelberglaan 100, 3584 CX Utrecht, The Netherlands

\begin{abstract}
Enterococci are important nosocomial pathogens with multiple intrinsic and acquired resistances to antibiotics. In the past, the majority of infections were caused by Enterococcus faecalis; however, an increase in Enterococcus faecium clinical isolates has been observed in recent years. The enterococcal surface protein (Esp) is expressed on the surface of most E. faecium clinical isolates and has been shown to be involved in biofilm formation. Here, E. faecium E1162 and its previously created insertion-deletion mutant of the esp gene, E. faecium E1162 $\Delta$ esp, were compared in a mouse bacteraemia model. Anti-Esp serum was tested for its capacity to mediate opsonophagocytic killing of E1162 in vitro and to protect against E. faecium bacteraemia. The inactivation of esp attenuated $E$. faecium virulence with reduced numbers of bacteria recovered from the kidneys in animals infected with the mutant compared to the wild-type strain $(P=0.035)$. Passive immunization with rabbit polyclonal serum raised against the recombinant $\mathrm{N}$-terminal Esp protein did not protect mice against $E$. faecium bacteraemia $(P>0.05)$. In contrast, mice passively immunized with polyclonal antiserum raised against lipoteichoic acid (LTA) from $E$. faecalis had lower numbers of $E$. faecium $\mathrm{E} 1162$ in the blood compared to mice immunized with normal rabbit serum. These results suggest that Esp contributes to $E$. faecium persistence in the host. However, in contrast to LTA, Esp does not seem to be a target for protective antibodies in E. faecium strain $\mathrm{E} 1162$ in mouse bacteraemia.
\end{abstract}

\section{INTRODUCTION}

Enterococcus faecalis and Enterococcus faecium are currently the third to fourth most commonly isolated nosocomial pathogens worldwide (Werner et al., 2008). The increased contribution of E. faecium relative to $E$. faecalis as a causative agent of nosocomial enterococcal infections, first observed in the USA and recently also found in Europe, is of major concern (Arias \& Murray, 2009; Top et al., 2008) because most E. faecium strains are increasingly resistant to both vancomycin and ampicillin. In the USA, resistance percentages against vancomycin and ampicillin for $E$. faecium isolated in critical care units increased to $80 \%$ and almost $100 \%$, respectively (Arias \& Murray, 2009). The rapid emergence of resistance to novel antimicrobial compounds in these bacteria significantly reduces options for antibiotic therapies. Population genetics of E. faecium disclosed that epidemic E. faecium strains are a genetically

Abbreviations: LTA, lipoteichoic acid; NRS, normal rabbit serum. distinct population compared to isolates from healthy persons (Willems et al., 2005). Enterococcal surface protein (Esp) is an important marker in epidemic strains since its presence seems to be limited to hospital-acquired $E$. faecium clones (Willems et al., 2001). In the present study, we investigated the role of Esp in the pathogenicity of bacteraemia and its potential role as a target for immunotherapy.

\section{METHODS}

Bacterial strains and growth conditions. E. faecium strain E1162 is a well-characterized clinical blood isolate harbouring the enterococcal surface protein gene (esp) (van den Bogaard et al., 1997). An insertion-deletion mutant in the esp gene of E. faecium strain E1162 was constructed previously by deleting a $287 \mathrm{bp}$ internal fragment and introducing a chloramphenicol resistance cassette (Heikens et al., 2007). Enterococci were grown at $37^{\circ} \mathrm{C}$ in tryptic soy broth (or CASO-broth; Merck) without agitation or on tryptic soy agar [TSA (or CASO agar); Merck]. 
Mouse bacteraemia model. Virulence of the E. faecium E1162 and E. faecium E1162 $\Delta$ esp strains was evaluated in a mouse bacteraemia model as described previously (Hufnagel et al., 2004), with minor modifications. Aliquots of bacterial overnight cultures were washed, resuspended in saline, shock-frozen and stored at $-80{ }^{\circ} \mathrm{C}$. For each experiment, the concentration of bacterial stocks was confirmed by viable counts. Two groups of seven female BALB/c mice (6-8 weeks old) were infected intravenously via the tail vein with $1.02 \times 10^{9}$ c.f.u. per animal for the E1162 wild-type strain and $1.76 \times 10^{9}$ c.f.u. per animal for E1162 $\Delta$ esp. The animals were sacrificed after $24 \mathrm{~h}$, blood was collected by cardiac puncture and the kidneys were harvested and homogenized. The number of bacteria in blood and kidney homogenates was determined by plating serial dilutions onto TSA plates and c.f.u. were counted the next day. The number of bacteria was expressed as c.f.u. (ml blood) $)^{-1}$ or c.f.u. (g homogenized kidney) ${ }^{-1}$

Opsonophagocytic activity of the anti-Esp serum. An opsonophagocytic assay was used as previously described to test rabbit antiEsp serum for the presence of opsonic antibodies directed against strain E1162 (Theilacker et al., 2006). Fresh polymorphonuclear neutrophils (PMNs) were isolated from healthy volunteers and immune rabbit serum raised against lipoteichoic acid (LTA) purified from E. faecalis strain 12030 (Theilacker et al., 2006) or against the recombinant N-terminal domain of Esp (anti-Esp serum) (Van Wamel et al., 2007) was used in various concentrations ranging from $1: 1000$ to $1: 25$. Newborn rabbit serum (Cedarlane Laboratories) diluted $1: 15$ and absorbed with the target bacterial strain (E. faecium strain E1162) for $1 \mathrm{~h}$ at $4{ }^{\circ} \mathrm{C}$ served as a source of complement. Bacteria were prepared by growing them to mid-exponential phase, with subsequent washing and diluting to obtain a final bacterium : PMN ratio of $1: 1$. Tubes lacking complement, PMNs or serum were used as negative controls. The per cent killing was calculated by comparing the mean of the negative controls with the colony counts obtained after incubation for $90 \mathrm{~min}$ at $37{ }^{\circ} \mathrm{C}\left(T_{90}\right)$ on a rotor rack by use of the following formula: [(mean c.f.u. controls-mean c.f.u. at $\left.T_{90}\right) /($ mean c.f.u. controls) $] \times 100$.

Protection studies. Rabbit anti-Esp serum raised against the $\mathrm{N}$ terminal portion of the protein (Van Wamel et al., 2007) was tested for its ability to confer protection against E. faecium bacteraemia in mice. The N-terminal portion is probably the surface-exposed part of the Esp protein (Heikens et al., 2007) and was shown to be sufficient for mediating biofilm formation in $E$. faecalis and for inhibiting initial adherence of E. faecium to polystyrene (Van Wamel et al., 2007; Tendolkar et al., 2005). Groups of eight BALB/c mice were injected in the tail vein with either $200 \mu \mathrm{l}$ rabbit anti-Esp serum, $200 \mu \mathrm{l}$ anti-LTA serum or $200 \mu \mathrm{l}$ normal rabbit serum (NRS), respectively. After $24 \mathrm{~h}$, all mice were challenged i.v. with $2 \times 10^{9}$ c.f.u. E. faecium strain E1162 and after an additional $24 \mathrm{~h}$ all mice were sacrificed. The blood was drawn and the kidneys were harvested and cultivated quantitatively as described above.

\section{RESULTS AND DISCUSSION}

\section{Experimental bacteraemia model}

To study the persistence of strain E1162 and its isogenic Esp-deficient mutant in a bacteraemia model, mice were injected via the tail vein with a high bacterial inoculum of both wild-type and mutant. In these experiments, the animals were sacrificed after $24 \mathrm{~h}$ because all the mice had completely cleared the bacteria from blood and kidneys after $72 \mathrm{~h}$. At $24 \mathrm{~h}$, quantitative counts of bacteria in the blood did not differ between E1162 wild-type and E1162 $\Delta$ esp infection. The mean bacterial numbers recovered from blood were 70 c.f.u. $\mathrm{ml}^{-1}$ for the wild-type bacteria and 50 c.f.u. $\mathrm{ml}^{-1}$ for the Esp-deficient mutant. However, the bacterial load in homogenized kidneys from mice infected with the Esp-deficient mutant was significantly lower compared to infection with wild-type bacteria $(P=0.035$, Fig. 1), suggesting a specific role of Esp in invasion in the renal parenchyma and/or persistence in the kidney.

\section{Opsonic and protective activity of anti-Esp serum}

Since Esp seemed to be associated with infectivity in a mouse bacteraemia model, we evaluated the efficacy of immune serum raised against the $\mathrm{N}$-terminal part of Esp using this serum as a source of antibodies in an opsonic killing assay. However, even at high concentrations of the serum $(1: 25)$, no significant bacterial killing (i.e. more than $50 \%$ ) was observed. In comparison, using serum raised against LTA from E. faecalis, more than $75 \%$ killing of E1162 even at relatively low serum concentrations (i.e. 1:500) was observed (Fig. 2).

Mice were also passively immunized with anti-Esp serum or with NRS and subsequently infected with strain E1162. All mice showed similar bacterial counts in blood (data not shown) and in kidneys $24 \mathrm{~h}$ after infection (Fig. 3). This indicates that anti-Esp antibodies do not protect against $E$. faecium infection. In additional experiments, NRS and anti-LTA serum were compared for their ability to protect mice against bacterial infection with strain E1162 under the same experimental conditions. Passive immunization with anti-LTA serum significantly reduced bacterial counts in blood (2.71 $\log _{10}$ reduction) and kidneys (3.45 $\log _{10}$ reduction $)(P<0.05)$.

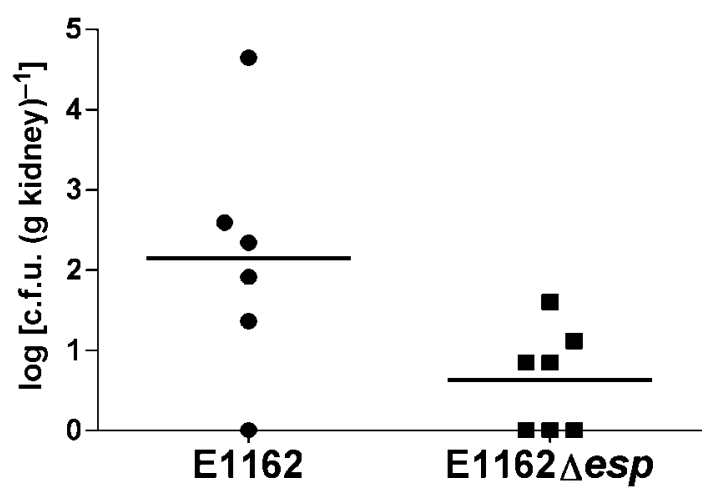

Fig. 1. Mouse bacteraemia model. Mice were challenged i.v. with the E1162 strain $\left(1.02 \times 10^{9}\right.$ c.f.u. per animal) or with the E1162 $\Delta$ esp strain $\left(1.76 \times 10^{9}\right.$ c.f.u. per animal). After $24 \mathrm{~h}$, the animals were sacrificed and the kidneys were harvested. The mean number of bacteria in kidney homogenates was expressed as c.f.u. (g homogenized kidney) $)^{-1}(P=0.035$, using two-tailed $t$-test). 


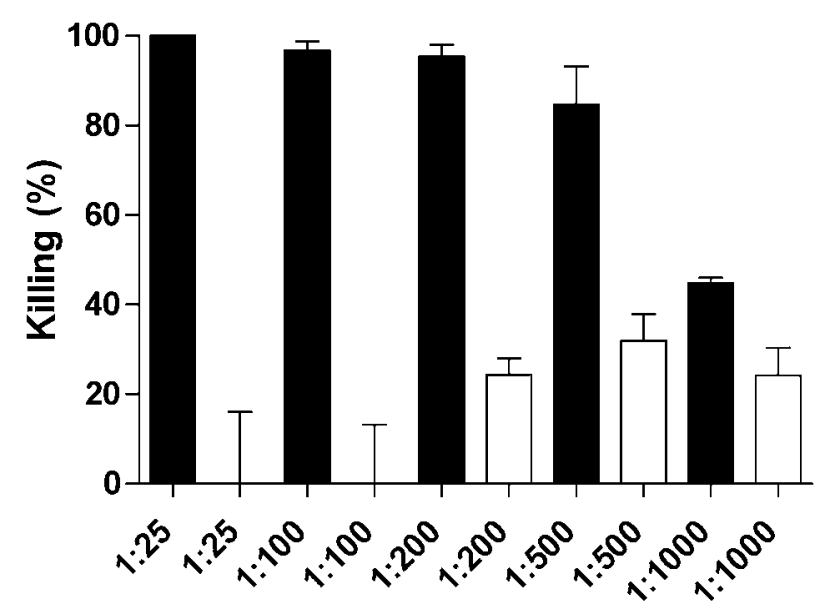

Fig. 2. Opsonic activity of the anti-Esp serum ( $\square$ ) compared with anti-LTA serum ( $\boldsymbol{\square})$. The target of the opsonic antibodies in strain E1162 was investigated using rabbit anti-Esp and anti-LTA sera in an opsonophagocytic assay. Bars represent the mean of four determinations and error bars represent SEM.

Several factors have been associated with virulence in enterococci (Jett et al., 1994; Koch et al., 2004). Shankar and colleagues described Esp in E. faecalis, which is contained on a $153 \mathrm{~kb}$ pathogenicity island (PAI) and has homology to alpha-C and Rib proteins in group B streptococci (Shankar et al., 1999, 2002). A few years later, Willems et al. (2001) and Baldassarri et al. (2001) found an esp homologue in E. faecium and in addition discovered that epidemic E. faecium isolates causing hospital infections carry this esp gene more frequently than faecal isolates. Furthermore, it was determined that E. faecium esp is also part of a putative PAI that seems to be associated with nosocomial outbreaks (Leavis et al., 2004). The E. faecalis Esp protein has been shown to be associated with biofilm

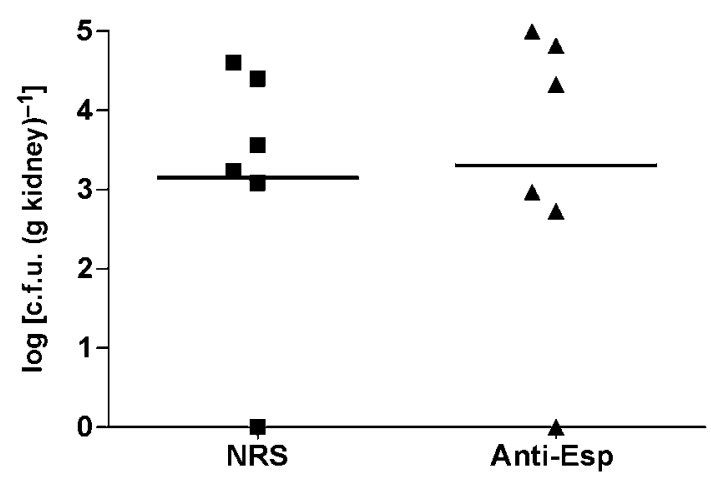

Fig. 3. Protection against enterococcal bacteraemia using antiEsp serum and NRS. Mice were challenged with $2 \times 10^{9}$ c.f.u. $24 \mathrm{~h}$ after vaccination and sacrificed $24 \mathrm{~h}$ later. The mean number of bacteria in kidney homogenates was expressed as c.f.u. ( $g$ homogenized kidney $)^{-1}$ ( $P>0.05$, using two-tailed $t$-test). formation on polystyrene (Tendolkar et al., 2004). However, since Kristich et al. (2004) and Toledo-Arana et al. (2001) were able to demonstrate that biofilm formation also takes place in the absence of Esp, it is likely that Esp represents only one of a number of different mechanisms by which E. faecalis produces biofilm. Insertion-deletion mutation of the esp gene in a hospitalacquired E. faecium isolate demonstrated the role of $E$. faecium Esp in initial adherence and biofilm formation on polystyrene surfaces (Heikens et al., 2007). By using this Esp-deficient mutant, it was demonstrated that Esp is involved in adhesion of E. faecium to uroepithelial cells and that the presence of this protein prolonged infection in the kidneys and bladder of mice (Leendertse et al., 2009). The role of Esp in a mouse urinary tract infection model was also demonstrated for E. faecalis (Shankar et al., 2001), which emphasizes that Esp is an important virulence determinant in urinary tract infections caused by either $E$. faecium or E. faecalis. Esp disruption did not affect the course of peritonitis in mice (Leendertse et al., 2009), and did not affect bacterial adhesion to colonic carcinoma cells in vitro or intestinal colonization and translocation to lymph nodes in mice (Heikens et al., 2009). In E. faecalis, Esp is also not essential for intestinal cell adhesion and translocation (Pultz et al., 2005), reaffirming the E. faecium results. The importance of E. faecium Esp in experimental rat endocarditis and mouse urinary tract infection probably can be explained by the fact that these models represent classical biofilm infections.

Our results suggest that passive immunization with antibodies against Esp does not confer protection against E. faecium in a mouse bacteraemia model. However, in other Gram-positive bacteria, antibodies to homologues of Esp, such as Rib and $\alpha$-like protein of Streptococcus agalactiae, have been shown to confer immune protection in mice (Lachenauer \& Madoff, 1996; StalhammarCarlemalm et al., 1993). So far, only an ABC transporter in E. faecium (Burnie et al., 2002), the Gls24 protein (Teng et al., 2005) and the collagen adhesin Ace of E. faecalis (Singh et al., 2010) have been experimentally shown to elicit a protective immune response in animal models. The susceptibility of E1162 to opsonic killing mediated by anti-LTA antibodies confirms previous studies by our group (Huebner et al., 1999, 2000) in which LTA was shown to be the predominant target for protective antibodies in about $25 \%$ of E. faecalis and $33 \%$ of $E$. faecium strains. In summary, the data presented here confirm the role of Esp in the pathogenicity of E. faecium, but indicate that this antigen is probably not a suitable vaccine candidate.

\section{ACKNOWLEDGEMENTS}

This work was supported by the European Union Sixth Framework Programme 'Approaches to Control multi-resistant Enterococci (ACE): studies on molecular ecology, horizontal gene transfer, fitness and prevention' (J.H. and R.W). 


\section{REFERENCES}

Arias, C. A. \& Murray, B. E. (2009). Antibiotic-resistant bugs in the 21st century - a clinical super-challenge. $N$ Engl J Med 360, 439-443. Baldassarri, L., Bertuccini, L., Ammendolia, M. G., Gherardi, G. \& Creti, R. (2001). Variant esp gene in vancomycin-sensitive Enterococcus faecium. Lancet 357, 1802.

Burnie, J., Carter, T., Rigg, G., Hodgetts, S., Donohoe, M. \& Matthews, R. (2002). Identification of ABC transporters in vancomycin-resistant Enterococcus faecium as potential targets for antibody therapy. FEMS Immunol Med Microbiol 33, 179-189.

Heikens, E., Bonten, M. J. \& Willems, R. J. (2007). Enterococcal surface protein Esp is important for biofilm formation of Enterococcus faecium E1162. J Bacteriol 189, 8233-8240.

Heikens, E., Leendertse, M., Wijnands, L., van Luit-Asbroek, M., Bonten, M. J., Van Der Poll, T. \& Willems, R. J. (2009). Enterococcal surface protein Esp is not essential for cell adhesion and intestinal colonization of Enterococcus faecium in mice. BMC Microbiol 9, 19.

Huebner, J., Wang, Y., Krueger, W. A., Madoff, L. C., Martirosian, G., Boisot, S., Goldmann, D. A., Kasper, D. L., Tzianabos, A. O. \& other authors (1999). Isolation and chemical characterization of a capsular polysaccharide antigen shared by clinical isolates of Enterococcus faecalis and vancomycin-resistant Enterococcus faecium. Infect Immun 67, 1213-1219.

Huebner, J., Quaas, A., Krueger, W. A., Goldmann, D. A. \& Pier, G. B. (2000). Prophylactic and therapeutic efficacy of antibodies to a capsular polysaccharide shared among vancomycin-sensitive and -resistant enterococci. Infect Immun 68, 4631-4636.

Hufnagel, M., Koch, S., Creti, R., Baldassarri, L. \& Huebner, J. (2004). A putative sugar-binding transcriptional regulator in a novel gene locus in Enterococcus faecalis contributes to production of biofilm and prolonged bacteremia in mice. J Infect Dis 189, 420-430.

Jett, B. D., Huycke, M. M. \& Gilmore, M. S. (1994). Virulence of enterococci. Clin Microbiol Rev 7, 462-478.

Koch, S., Hufnagel, M., Theilacker, C. \& Huebner, J. (2004). Enterococcal infections: host response, therapeutic, and prophylactic possibilities. Vaccine 22, 822-830.

Kristich, C. J., Li, Y. H., Cvitkovitch, D. G. \& Dunny, G. M. (2004). Espindependent biofilm formation by Enterococcus faecalis. J Bacteriol 186, 154-163.

Lachenauer, C. S. \& Madoff, L. C. (1996). A protective surface protein from type $\mathrm{V}$ group $\mathrm{B}$ streptococci shares $\mathrm{N}$-terminal sequence homology with the alpha C protein. Infect Immun 64, 4255-4260.

Leavis, H., Top, J., Shankar, N., Borgen, K., Bonten, M., van Embden, J. \& Willems, R. J. (2004). A novel putative enterococcal pathogenicity island linked to the esp virulence gene of Enterococcus faecium and associated with epidemicity. J Bacteriol 186, 672-682.

Leendertse, M., Heikens, E., Wijnands, L. M., van Luit-Asbroek, M., Teske, G. J., Roelofs, J. J., Bonten, M. J., van der Poll, T. \& Willems, R. J. (2009). Enterococcal surface protein transiently aggravates Enterococcus faecium-induced urinary tract infection in mice. J Infect Dis 200, 11621165.

Pultz, N. J., Shankar, N., Baghdayan, A. S. \& Donskey, C. J. (2005). Enterococcal surface protein Esp does not facilitate intestinal colonization or translocation of Enterococcus faecalis in clindamycin-treated mice. FEMS Microbiol Lett 242, 217-219.

Shankar, N., Lockatell, C. V., Baghdayan, A. S., Drachenberg, C., Gilmore, M. S. \& Johnson, D. E. (2001). Role of Enterococcus faecalis surface protein Esp in the pathogenesis of ascending urinary tract infection. Infect Immun 69, 4366-4372.
Shankar, N., Baghdayan, A. S. \& Gilmore, M. S. (2002). Modulation of virulence within a pathogenicity island in vancomycin-resistant Enterococcus faecalis. Nature 417, 746-750.

Shankar, V., Baghdayan, A. S., Huycke, M. M., Lindahl, G. \& Gilmore, M. S. (1999). Infection-derived Enterococcus faecalis strains are enriched in esp, a gene encoding a novel surface protein. Infect Immun 67, 193-200.

Singh, K. V., Nallapareddy, S. R., Sillanpaa, J. \& Murray, B. E. (2010). Importance of the collagen adhesin Ace in pathogenesis and protection against Enterococcus faecalis experimental endocarditis. PLoS Pathog 6, e1000716.

Stalhammar-Carlemalm, M., Stenberg, L. \& Lindahl, G. (1993). Protein rib: a novel group B streptococcal cell surface protein that confers protective immunity and is expressed by most strains causing invasive infections. J Exp Med 177, 1593-1603.

Tendolkar, P. M., Baghdayan, A. S., Gilmore, M. S. \& Shankar, N. (2004). Enterococcal surface protein, Esp, enhances biofilm formation by Enterococcus faecalis. Infect Immun 72, 6032-6039.

Tendolkar, P. M., Baghdayan, A. S. \& Shankar, N. (2005). The Nterminal domain of enterococcal surface protein, Esp, is sufficient for Esp-mediated biofilm enhancement in Enterococcus faecalis. J Bacteriol 187, 6213-6222.

Teng, F., Nannini, E. C. \& Murray, B. E. (2005). Importance of $g l_{s} 24$ in virulence and stress response of Enterococcus faecalis and use of the Gls24 protein as a possible immunotherapy target. J Infect Dis 191, 472-480.

Theilacker, C., Kaczynski, Z., Kropec, A., Fabretti, F., Sange, T., Holst, O. \& Huebner, J. (2006). Opsonic antibodies to Enterococcus faecalis strain 12030 are directed against lipoteichoic acid. Infect Immun 74, 5703-5712.

Toledo-Arana, A., Valle, J., Solano, C., Arrizubieta, M. J., Cucarella, C., Lamata, M., Amorena, B., Leiva, J., Penades, J. R. \& other authors (2001). The enterococcal surface protein, Esp, is involved in Enterococcus faecalis biofilm formation. Appl Environ Microbiol 67, $4538-4545$.

Top, J., Willems, R. \& Bonten, M. (2008). Emergence of CC17 Enterococcus faecium: from commensal to hospital-adapted pathogen. FEMS Immunol Med Microbiol 52, 297-308.

van den Bogaard, A. E., Mertens, P., London, N. H. \& Stobberingh, E. E. (1997). High prevalence of colonization with vancomycin- and pristinamycin-resistant enterococci in healthy humans and pigs in The Netherlands: is the addition of antibiotics to animal feeds to blame? J Antimicrob Chemother 40, 454-456.

Van Wamel, W. J., Hendrickx, A. P., Bonten, M. J., Top, J., Posthuma, G. \& Willems, R. J. (2007). Growth condition-dependent Esp expression by Enterococcus faecium affects initial adherence and biofilm formation. Infect Immun 75, 924-931.

Werner, G., Coque, T. M., Hammerum, A. M., Hope, R., Hryniewicz, W., Johnson, A., Klare, I., Kristinsson, K. G., Leclercq, R. \& other authors (2008). Emergence and spread of vancomycin resistance among enterococci in Europe. Euro Surveill 13, pii $=19046$.

Willems, R. J., Homan, W., Top, J., van Santen-Verheuvel, M., Tribe, D., Manzioros, X., Gaillard, C., Vandenbroucke-Grauls, C. M., Mascini, E. M. \& other authors (2001). Variant esp gene as a marker of a distinct genetic lineage of vancomycin-resistant Enterococcus faecium spreading in hospitals. Lancet 357, 853-855.

Willems, R. J., Top, J., van Santen, M., Robinson, D. A., Coque, T. M., Baquero, F., Grundmann, H. \& Bonten, M. J. (2005). Global spread of vancomycin-resistant Enterococcus faecium from distinct nosocomial genetic complex. Emerg Infect Dis 11, 821-828. 